\title{
Empresarização e controle organizacional: um estudo nos clu- bes de futebol em Santa Catarina
}

\author{
Enterprisation and Organizational Control: a study of soccer clubs of Santa Ca- \\ tarina
}

Carlos Everaldo Silva da Costa ${ }^{1}$

Rosimeri Carvalho da Silva

\section{Resumo}

O futebol é um dos principais esportes praticados no Brasil, tendo grande relação com a identidade do povo brasileiro. Sua divulgação no país, iniciada em 1894 junto a uma elite, não parou de se expandir e atinge hoje todas as classes sociais. O futebol é atualmente gerido por clubes que, na maioria, são organizações sem fins lucrativos, mas que parecem passar por transformações significativas em um processo de mercantilização do esporte. Este artigo busca analisar o quanto clubes que fizeram parte da série A1 (primeira divisão) do campeonato catarinense de futebol de 2000 a 2004 passam a utilizar mecanismos empresariais em suas ações e as transformações que tal utilização implica para o controle organizacional. Como fundamento do estudo, utiliza-se a teoria desenvolvida por Solè (2004) sobre empresarização e para o controle organizacional, entre outros autores, o modelo de Carvalho (1998). Percebeu-se um processo de empresarização acentuado em um clube (Figueirense) e mediano em outros quatro (Joinville, Avai, Chapecoense e Criciúma). Dois dos clubes analisados parecem oferecer maior resistência ao processo de empresarização.

Palavras-chave: controle organizacional; empresarização; futebol.

Abstract

Soccer is one of the main sports practiced in Brazil and is related to the identity of the Brazilian people. The spread of this sport in the country by the elite began in 1894 and it reaches all social classes nowadays. Currently, soccer is managed by clubs, which, in its majority, are non-profit organizations, but that seem to pass for significant transformations in a process of marketization of the sport. This work aims to analyze how clubs that had been part of the A1 series (first division) of the soccer championship in the period between 2000 and 2004, in the state of Santa Catarina, started to adopt management mechanisms in its actions. The study also analyzes the effects that such transformation has on organizational control. The theoretical foundations of this study were developed by Andreu Solè (2004) (enterprisation) and Carvalho (1998) (organizational control), among other authors. A process of accented enterprisation in a club (Figueirense) and a relative enterprisation in other four clubs was perceived (Joinville, Avai, Chapecoense and Criciúma). Two of the analyzed clubs seem to offer more resistance to the enterprisation process.

Key words: organizational control; enterprisation; soccer.

\footnotetext{
1 Mestre em Administração pela Universidade Federal de Santa Catarina. Professor da Universidade Federal de Alagoas - Campus Arapiraca. Endereço: Conjunto Santo Eduardo QUADRA 05, 986 , POçO, Maceió - Alagoas - Brasil EP - 57025245. E-mail: c_everaldo@hotmail.com.

2 Professora do Departamento de Ciências da Administração e do Curso de Pós-Graduação em Administração da Universidade Federal de Santa Catarina (CPGA/UFSC). Endereço: Universidade Federal de Santa Catarina - UFSC - Trindade - Florianópolis - Santa Catarina - Brasil - CEP 88040. E-mail: rosimeri@cse.ufsc.br.
}

Artigo recebido em novembro de 2006 e aceito para publicação em dezembro de 2006. 


\section{Introdução}

O futebol pode ser considerado um esporte de muita aceitação no Brasil, gerando debates em vários âmbitos da nossa sociedade. Do mesmo modo que comentam e discutem, as pessoas também praticam o futebol de várias formas. Pode-se encontrar, em uma dimensão, o futebol praticado como um "joguinho", uma "pelada" ou "rachinha" na porta de casa - segundo denominações populares - jogado com os pés descalços, com pares de sandálias utilizados como "travessões" e com times identificados pelo uso ou não de camisas. Igualmente, há os jogos em campos alugados com os amigos - sendo seus jogadores muitas vezes uniformizados - até se chegar aos campeonatos amadores feitos em bairros comunitários. Já em uma segunda dimensão, há o futebol profissional, com campeonatos estaduais, nacionais e internacionais organizados segundo uma lógica diferente.

A primeira dimensão do futebol parte do princípio de um jogo lúdico, que se pode aproximar daquilo que Ramos (1989) chama de prática substantiva na sua distinção entre racionalidade substantiva e instrumental. Nesse caso, prevalece o prazer de se praticar e discutir o futebol. As relações de identidade e o compartilhamento de valores são aspectos importantes nessa dimensão. Na segunda dimensão do futebol, as relações são modificadas e, embora laços de identidade não desapareçam de todo, questões profissionais e relações instrumentais começam a ter preponderância. Essa transformação parece vir se acentuando no presente à medida que os clubes se aproximam mais do mercado. Na análise que realizam sobre o fenômeno, Carvalho, Gonçalves e Alcântara (2003, p.252) afirmam que "isso decorre do fato de as organizações desportivas estarem incorporando novos significados aos seus agentes e instituições, frutos da paulatina ampliação de uma lógica orientadora das ações de mercado, que se reflete em diversas áreas, como o torcedor, o jogador, o jogo, o estádio e os relacionamentos". A adoção de uma lógica orientadora das ações de mercado faz com que os clubes de futebol adotem mecanismos empresariais de gestão.

Apesar de alguns estudos sobre futebol já terem sido feitos na área de estudos organizacionais, pretende-se contribuir, aqui, com uma análise na qual se observou o comportamento das organizações em relação aos mecanismos empresariais, a partir da perspectiva de Solé (2004) sobre o processo de empresarização e as transformações no controle interno das organizações futebolísticas. A adoção de mecanismos empresariais parece relevante na medida em que indica um processo de mercantilização crescente. A inserção de mecanismos empresariais na disposição de algumas organizações pode ter impacto sobre diversos processos desenvolvidos nas mesmas. Examinamos um dos processos considerados centrais no fenômeno organizacional, o controle. Nosso objetivo no estudo foi analisar o processo de empresarização nos clubes que participaram da primeira divisão do campeonato de Santa Catarina e a relação que esse processo pode ter com o controle nessas organizações.

A pesquisa teve cunho qualitativo. Realizamos um estudo comparativo de casos que pode ser classificado como descritivo-interpretativo, pois ao mesmo tempo em que procuramos descrever a transformação do controle nos clubes de futebol em Santa Catarina, a partir da análise do processo de empresarização, procuramos também compreender as relações entre as transformações ocorridas com o processo de empresarização e as consequiências para o controle organizacional dos clubes. Tal descrição caracterizou o estudo como histórico-estrutural (TRIVIÑOS, 1987), assim como a pesquisa foi classificada como seccional com perspectiva longitudinal (VIEIRA; ZOUAIN, 2004). Os dados sobre os clubes de futebol foram coletados em um ponto específico do tempo, mas procuramos reconstruir a história das organizações, bem como realizar um esforço de reconstituição das diversas fases do processo de empresarização, resultado este que não conseguimos alcançar.

A população foi composta por todos os clubes que disputaram a série "A1" (primeira divisão) do campeonato catarinense de futebol de 2000 a 2004, fazendo parte da amostra os clubes que se mantiveram nessa série, ou seja, sete clubes: Avaí, Chapecoense, Criciúma, Figueirense, Joinvile, Marcílio Dias e Tubarão. O nível de análise foi organizacional e a unidade de observação foi constituída pelo grupo de gerentes, diretores, representantes e funcionários antigos que fazem ou fizeram parte dos clubes estudados. 
Uma das formas de coleta de dados utilizada foi a observação direta, que além de se prestar a identificar e obter provas de certas suposições, ajudou a construir a categorização mental da realidade (MARCONI; LAKATOS, 1990). Além disso, foi feita uma pesquisa documental em jornais, Internet (sites da federação, sites esportivos, jornais eletrônicos e sites dos clubes), documentos históricos dos clubes e dos campeonatos e nos próprios clubes. Também foram feitas entrevistas semi-estruturadas com dirigentes, diretores, representantes, funcionários antigos e ex-integrantes dos clubes selecionados, totalizando 18 entrevistas, com duração média de 40 minutos, realizadas entre 8 de novembro e 23 de dezembro de 2004.

A seguir realizamos uma rápida discussão sobre o fenômeno que focalizamos neste estudo, o futebol. Na parte seguinte, apresentamos os traços principais do modelo de empresa desenvolvido por Solé (2004) selecionados para esta pesquisa como fundamento para a análise do processo de empresarização dos clubes de futebol. No que diz respeito ao controle nos baseamos, sobretudo, no modelo desenvolvido por Carvalho (1998), que discutimos, juntamente com alguns conceitos fundamentais desenvolvidos por estudiosos da área, na quarta parte do artigo. Por fim, discutimos os resultados encontrados e apresentamos nossas reflexões à guisa de conclusão da presente discussão.

\section{Sociedade: jogo, esporte e o futebol}

O esporte parece ter tido um papel importante na busca de distinção dos grupos sociais. Segundo Brunoro (1997), a extraordinária rapidez com que todas as formas de esporte organizado conquistaram a sociedade burguesa, entre 1870 e 1900, sugere que o esporte preenchia uma necessidade social consideravelmente maior que a de exercícios ao ar livre. Paradoxalmente, na Inglaterra, seu proletariado industrial e uma nova burguesia, ou classe média, emergiram ao mesmo tempo como grupos autoconscientes, que se definiam um contra o outro por meio de maneiras e ações coletivas. $O$ esporte, nesse sentido era uma das maneiras mais importantes de realizar aquela definição dividindo as classes. Assim, "a história do esporte moderno surge nas modificações impostas pelas classes inferiores, no que se chamava esporte, determinado por fatores, como as mudanças exigidas no 'estilo de vida' da burguesia da época e nos passatempos da classe operária." (PILLATI, 1999, p.274).

Pode-se perceber nessa explicação do desenvolvimento do esporte o papel que desempenhou desde o início na construção de identidades sociais. A evolução dos estudos sobre o esporte nos leva também à compreensão do desenvolvimento de valores instrumentais que culminam no desenvolvimento da indústria do esporte. Nesse sentido, Bourdieu (1983) trabalha a fronteira móvel entre o jogo e o esporte. Para Bourdieu (1983) o esporte é entendido como um conjunto de práticas e de consumos esportivos oferecidos a agentes sociais por instituições para cumprir uma demanda social, sendo um fenômeno cultural com uma lógica e história próprias. A história do esporte, para o autor, surge quando há o início de um campo de concorrência, no interior do qual o esporte apareceu, definido como prática esportiva, irredutível a um simples jogo. Assim, o campo esportivo surge da ruptura das atividades antes consideradas lúdicas (jogo) para uma baseada na competência específica (esporte). As modalidades vêm de uma evolução de um jogo ancestral para se tornarem esporte moderno a partir do momento em que seu campo foi organizado. Os jogos ainda existem e existirão segundo Pilatti (1999), assim como muitos jogos se desenvolverão alcançando um caráter organizado.

Atualmente, o esporte como um dos fenômenos sociais e culturais mais importantes do século XX, segundo Roche (2002), tanto como espetáculo de massa quanto de prática livre e voluntária do cidadão, desenvolve-se através de entidades e organizações desportivas. "Entidades com origem associativa em seu princípio, às quais, posteriormente, se uniram corporações de caráter público e sociedades comerciais, levando o esporte a converter-se em objeto de consumo" (ROCHE, 2002, p.35). Partindo dessa lógica, o esporte, segundo Kasznar (2002), gera uma demanda econômica que se verifica quando o esporte visto e/ou praticado é remunerado, gerando fluxos de caixa e empregados assalariados. É nesse caso que o futebol, partindo de uma evolução histórica, baseado em um jogo, desenvolveu-se, tornou-se esporte e, atualmente, objeto de consumo como um produto qualquer. Essa transformação parece implicar cada vez mais organizações privadas na realização do esporte fazendo predominar um caráter utilitário na prática do futebol. Os valores inicialmente envolvidos na prática desse esporte parecem ir paulatinamente desaparecendo e dando lugar a relações cada vez mais profissionais, transformando, com base inclusive em leis federais, o caráter das organizações desportivas. ${ }^{1}$ Os clubes parecem 
assim adotar a forma de empresas, processo que poderá ser melhor elucidado com a compreensão do modelo de Solé (2004) sobre a empresa, que apresentamos a seguir.

\section{Empresarização: organização e empresa}

Solé (2004) afirma que há uma “confusão" em relação ao que é uma empresa e o que é uma organização, tanto para estudiosos da economia, sociologia, psicologia quanto da história. Para o autor, a maioria dos estudiosos quando fala em organização, pensa em empresa. Etzioni (1967, p.7) já afirmava que

a nossa sociedade é uma sociedade de organizações. Nascemos em organizações, somos educados por organizações, e quase todos nós passamos a vida a trabalhar para organizações. Passamos muitas de nossas horas de lazer a pagar, a jogar e a rezar em organizações. Quase todos nós morremos numa organização.

Para Blau e Scott (1970), o que todas as organizações têm em comum é que um número de homens se organizou em uma unidade social - uma organização - estabelecida com o propósito explícito de chegar a certas finalidades. Se

a feitura de uma tarefa requer mais do que um punhado de homens trabalhando juntos, eles não podem agir deixando cada um fazer aquilo que julgar que deva ser feito; antes é preciso que eles se organizem. Estabelecem, então, um clube ou uma empresa, organizam um sindicato [...] e formulam regras que irão governar as relações entre os membros da organização e os deveres de cada um deles. (BLAU; SCOTT, 1970, p.13).

Como essas, podemos encontrar várias definições para organização, a maioria delas, segundo Solé (2004), não consegue escapar da visão predominante de empresa, da linguagem da empresa.

Solé define organização como um "conjunto de relações entre humanos" e, empresa como um "conjunto - singular - de relações entre humanos" (SOLÉ, 2004, p.1). A hipótese de Solé (2004) é que nosso mundo está voltado para a organização que o caracteriza, a empresa, e que esse mundo está organizado por e para a empresa, podendo assim ser entendido como um mundo-empresa. Logo, devido à confusão existente na literatura, da perspectiva do autor, entre organização e empresa, faz-se necessário esclarecer esse último conceito. De acordo com Solé (2004), a distinção da empresa diante das demais organizações é verificada a partir de cinco postulados gerais. Para o autor a empresa é: (1) um conjunto - singular - de relações entre humanos; (2) um fenômeno social total, ou seja, é uma organização econômica, social, política, psicossocial, jurídica etc., o que supõe um enfoque transdisciplinar; (3) é uma organização histórica, ou seja, não é natural ao ser humano, surgiu no tempo em determinado momento e pode vir a desaparecer; (4) uma organização característica e fundamental do mundo que se considera moderno e desenvolvido. A empresa organiza esse mundo, assim, as relações que caracterizam a empresa são aquelas que caracterizam o mundo; e (5) como toda organização humana, a empresa é um evento contingente da história humana que poderia ter tomado outro rumo, e que não necessariamente a empresa deveria aparecer obrigatoriamente como defendem Marx e Smith.

É dessa perspectiva que Solé constrói uma teoria na qual se pode identificar um tipo ideal de empresa, descrito através de 22 traços. Tendo desenvolvido uma teoria transdisciplinar da empresa, Solé apresenta e desenvolve traços que, embora extremamente importantes e fontes, certamente, de futuros proveitosos trabalhos sobre o fenômeno, não podem ser, abordados em um único estudo devido às exigências de abrangência, tanto teórica quanto empírica. A amplitude do tipo ideal desenvolvido pelo autor nos levou, então, a selecionar alguns dos traços evidenciados a fim de analisar o processo de empresarização nos clubes de futebol, traços esses que dizem que a empresa é: a) uma organização que concebe, produz e vende mercadorias; b) capital e lucro, ou seja, é uma organização com moeda, capital e benefício econômico; c) uma organização com escritura e contabilidade; d) uma propriedade privada; e) uma organização salarial; e f) uma organização que produz linguagem.

O desenvolvimento de tal teoria responde a uma percepção crescentemente compartilhada por vários estudiosos acerca da influência da empresa no mundo atual. A empresa parece ter se convertido no modelo único para todas as demais organizações ,sejam elas governamentais, culturais e sociais, com ou sem fins lucrativos. Esse 
modelo impõe as ferramentas, a linguagem, os métodos, as técnicas e as práticas características das empresas. Compreender, portanto, esse processo de empresarização é essencial para os estudos organizacionais contemporâneos em vários de seus aspectos. Nós decidimos, em função de seu caráter central nas organizações, analisar as relações da empresarização com o controle organizacional dos clubes de futebol de Santa Catarina.

\section{Controle organizacional: evolução e tipologia}

O controle, segundo Hofstede (1996), constitui alvo da atenção de diversos autores da área de estudos organizacionais. Sua importância, segundo Das (1989), é que apresenta uma grande associação com outros aspectos funcionais da organização. Tannenbaum $(1975$, p.15) diz que "caracterizar uma organização de acordo com o seu padrão de controle é descrever um aspecto essencial e universal da organização que cada membro deve enfrentar e ao qual deve ajustar-se. Organização implica controle [...]”. Dessa forma, estar numa situação de controle, segundo Chiapello (1996), vem a significar que o comportamento de uma pessoa é influenciado por seu próprio grupo de indivíduos. Na abordagem de Faria (2004), o exercício do controle não se dá sem resistência por parte dos trabalhadores, e com isso quem controla busca realçar e legitimar suas ações para que não haja indagações por parte dos controlados.

O controle pode ser definido através de uma abordagem evolutiva. A definição de Tanennbaum (1975, p.18), a mais utilizada pela literatura especializada, diz que o controle vem a ser "qualquer processo, no qual uma pessoa, grupo de pessoas ou organizações de pessoas determinam, e intencionalmente afetam, o comportamento de uma outra pessoa, grupo ou organização". Definição essa que desconsidera as relações de poder específicas das organizações e inclui processos que não podem ser considerados constituintes do controle organizacional. Chiapello (1996), por outro lado, define o controle como uma influência criadora de ordem. Silva (2003, p.800) seguindo a mesma perspectiva, define-o como "um processo de busca de redução de incerteza", no qual o controle tem um sentido mais amplo, que seria o de indagar não só sobre o controle interno, mas sim do controle que as organizações buscam alcançar sobre diversos aspectos. O controle, assim, seria busca da redução da incerteza para o alcance dos interesses da organização, interesses esses, definidos pelos grupos detentores de poder na mesma.

O controle foi exercido nas organizações através de diferentes mecanismos que, habitualmente, são apresentados de uma perspectiva evolucionista, seguindo do controle pré-capitalista na direção do controle difuso das organizações contemporâneas, segundo Hatch (1997) e Carvalho (1998). Nessa evolução, diferentes mecanismos de controle organizacional foram sendo desenvolvidos à medida que as contradições dentro e entre as estruturas de controle também vieram a se manifestar (MINTZBERG, 1995). Crises surgiram e formas alternativas de controle foram sendo desenvolvidas, segundo a explicação de Burris (1989). Segundo Carvalho (1998, p.2), a evolução do controle em seu início

se manifesta na emergência de uma nova dinâmica do sistema fabril caracterizada pela separação do trabalhador dos meios de produção e a concentração da mão-de-obra nas fábricas urbanas. A aparição da alienação, por um lado, e a divisão do trabalho, por outro, são conseqüências visíveis que revolucionaram o processo de trabalho.

Nessas fábricas, de acordo com Burris (1989) e Mintzberg (1995), o controle simples permitiu, na época, a acumulação capitalista. Esse controle permeia todo o processo de trabalho e seu principal meio de direcionar o comportamento dos empregados é através da aplicação de sanções. É mais utilizado em tarefas repetitivas. Nesse contexto, Mintzberg (1995) enfatiza a supervisão direta na organização baseada na vigilância direta de um pequeno grupo de trabalhadores por um superior imediato.

A coerção e a rígida hierarquia no controle simples estavam transparentes e eram pobremente legitimadas, conduzindo à resistência do trabalhador, tornando-se bem menos eficazes com o crescimento das empresas capitalistas durante o século XIX. Em face da nova organização do trabalho, de acordo com Burris (1989), o controle simples entra em decadência e surgem alternativas para o mesmo, através do controle técnico, burocrático e do profissional. O controle técnico, segundo Motta (2002), está baseado em parâmetros altamente especializados, tarefas operacionais rotinizadas; e procedimentos muito padronizados no núcleo operacional. A má- 
quina dita o ritmo de trabalho dos funcionários. Esse controle embutido no sistema mecânico isola o trabalhador que apenas executa o trabalho. Tanto o controle simples quanto o técnico, segundo Mintzberg (1995) e Carvalho (1998), são formas dominantes de controle. Isso, devido ao fato de que a imposição e a supervisão direta eram os modos de se exercê-lo. Desde então, segundo os autores, formas hegemônicas surgiram no intuito de fazer valer o compromisso e a legitimação como forma de controle. As formas hegemônicas se manifestam nos controles: burocrático, profissional, tecnocrático e difuso.

O controle burocrático se baseia na padronização e formalização de procedimentos (MINTZBERG, 1995). Carvalho (1998, p.2) afirma que a burocracia se configura nesse sentido

como o primeiro modelo de organização que utiliza mecanismos indiretos e menos visíveis de controle ao inscrever a regulamentação das atividades, a especialização, a hierarquia e a divisão do trabalho em um conjunto de mecanismos impessoais.

No controle burocrático, a orientação está voltada para essas normas, no sentido de que cada cargo é composto por um especialista na função ou na tarefa, com ênfase alocada no cargo e não na pessoa.

O controle profissional, segundo Carvalho (1998) e Burris (1989), é estabelecido através de códigos éticos, status do grupo, auto-regulação, formalização da capacitação, conhecimento profissional e não no tempo de serviço ou regras de antigüidade, como característico da burocracia. Tal controle já está preestabelecido no treinamento antes da inserção do trabalhador na organização e a especialização é enfatizada no trabalho horizontal. Quando composto por um número expressivo de profissionais, segundo Mintzberg (1995), o núcleo operacional tem autonomia quase plena em seu trabalho.

No processo de evolução, Burris (1989) focaliza o controle tecnocrático, caracterizado por uma maior legitimidade, já que enfatiza a importância do conhecimento, da perícia e da igualdade de oportunidades no emprego. Esse controle, segundo Burris (1989, p.1), "integra antecipadamente as formas de controle organizacional, particularmente o controle técnico, o controle burocrático e o controle profissional". Nesse caso temos os exemplos "de atividades de investigação científica, de alto nível de formação, adequando-se melhor ao tipo de controle tecnocrático, no qual um contexto de competitividade exerce um papel significativo." (CARVALHO, 1998, p.37). Esse controle "resulta das transformações ocorridas na sociedade, nomeadamente o avanço da tecnologia e a globalização." (MONTE, 2003, p.272).

O controle difuso aparece como o último patamar nessa evolução, segundo Hatch (1997) e Carvalho (1998). Da perspectiva de Etzioni (1967) seria uma forma de controle característica de organizações normativas, baseada em valores e crenças internalizados pelos integrantes das organizações. A tomada de decisão nesse tipo de controle está ligada aos valores culturais em lugar de materializar-se sobre aspectos mais concretos desse processo, como regras escritas (CARVALHO, 1998). Nas organizações que se apóiam nesse controle há a tendência de haver poucos "oficiais" e poucos líderes informais (ETZIONI, 1967). Os líderes formais nesse tipo de organizações "controlam eficientemente quase todos os participantes da organização" (ETZIONI, 1967, p.102). Constituem nesse contexto, "uma forma de controle mais difícil de exercer, mas com a qual se obtém mais eficácia, já que o subordinado restringe voluntariamente a gama de estímulos aos quais vai prestar atenção" (CARVALHO, 1998, p.39). Em síntese, a partir dos autores abordados, o controle difuso pode ser alcançado através da identificação e do poder de mobilização voluntária que uma pessoa consegue exercer sobre um grupo de pessoas. A limitação nesse caso não é explicitamente violenta. Esse controle caracterizaria, segundo Courpasson (2000), uma dominação suave, característica das transformações pelas quais vêm passando as organizações burocráticas.

Podemos, para os fins deste estudo, sintetizar os tipos de controle descritos pelos estudiosos em três tipos básicos: o controle direto, o controle burocrático e o controle difuso. ${ }^{3} \mathrm{O}$ controle direto, é exercido quando as ordens são impostas, através de uma vigilância expressa e presente. É o controle exercido em organizações totais, como fábricas, indústrias e asilos $(\mathrm{HATCH}, 1997)$. Aqui, a subordinação real do trabalho é ponto importante. Motta (2002, p.38), discutindo o controle direto, afirma que o

\footnotetext{
${ }^{3}$ Esse controle também é conhecido, entre outras denominações, por controle cultural. Porém, neste trabalho, seguindo a base da tipologia utilizada pela autora, será denominado difuso.
} 
controle devia ser, na opinião dos teóricos da Escola Clássica, mais cerrado. Assim, advogavam o controle por supervisão em lugar daquele por resultados. O supervisor devia seguir, detalhadamente, o trabalho dos subordinados em todas as suas fases, pois se admitia haver uma única forma de realizálo.

Segundo Wagner e Hollenbeck (2000), a supervisão direta indica quando um membro é responsável pelas atividades de um grupo de pessoas. Enfim, Mintzberg (1995) associa o controle direto a uma organização com estrutura simples, no qual o proprietário ou a cúpula não buscam utilizar os procedimentos burocráticos.

O segundo tipo de controle identificado é o burocrático. Em uma organização burocrática, o controle se fundamenta em normas, na estrutura hierárquica, e as tarefas passam a ser mais especializadas (MINTZBERG, 1995). Desse modo, o controle ocorre através de normas formais estabelecidas previamente. Uma clara divisão vertical e horizontal do trabalho, a qual define os requisitos técnicos dos cargos e o nível de profissionalização exigido pelas atividades executadas na organização. Em tal caso, os requisitos técnicos irão indicar previamente a função, de forma específica e especializada, de cada profissional. A tomada de decisão tende a se centralizar quando esse tipo de controle predomina. O controle burocrático é utilizado em organizações econômicas e a base do engajamento é o cálculo, desenvolvido de forma impessoal (HATCH, 1997; SILVA, 2003).

Através de um "bombardeio" ideológico da organização para com o funcionário - a partir da disseminação de valores que por este é compartilhado, é que a organização busca reproduzir sua ideologia de forma dominante, exercendo um tipo de controle invisível. A ideologia da organização se transforma em um valor máximo para o indivíduo (FARIA, 2004). Quando esse tipo de controle predomina, há um esforço evidente das organizações para a captura da subjetividade dos indivíduos, através de diferentes atividades (FARIA, 2004). O controle difuso é baseado na ideologia e identificação como base de engajamento, segundo Silva (2003), e assim controla as pessoas nessas organizações através dos aspectos culturais. Aqui, os pressupostos culturais são as bases do controle, pois nesse caso as pessoas comungam com uma visão de mundo semelhante. A manipulação das premissas sobre as quais os indivíduos que integram a organização tomarão suas decisões é um aspecto central dessa forma de controle. É necessário que um conjunto de valores centrais seja compartilhado para que a organização possa exercer seu domínio sem a necessidade de regras escritas e vigilância física. Por isso, a seleção dos integrantes e o desenvolvimento de programas de ação que disseminem tais valores passam a ser prioritários no que diz respeito à preparação dos integrantes.

Pagès (1993, p.44) comenta que

à medida que as empresas se ampliam, o controle exercido a partir dos principais centros de decisões corre o risco de frear seu desenvolvimento e perder sua eficácia. Precisam, pois, desenvolver "técnicas de administração à distância" que permitam aos dirigentes manter seu controle sobre conjuntos cada vez mais extensos, dando a possibilidade àqueles que gerenciam as diferentes unidades de produção de exercerem eficazmente suas próprias responsabilidades.

Segundo o autor, um sistema de regras é criado onde a autonomia e o controle se reforçam mutuamente, substituindo a gestão tradicional de delegação de poder por via hierárquica.

A relação entre os mecanismos de controle e os tipos organizacionais já foi claramente desenvolvida em estudos como o de Etzioni (1967). Com base nesse estudo, podemos afirmar que em organizações econômicas, logo, em organizações que apresentam mais acentuadamente os traços do tipo ideal de empresa, o controle burocrático seria predominante e o envolvimento dos integrantes seria caracterizado pelo cálculo. Já em organizações onde o controle difuso predomina, o envolvimento é, sobretudo, baseado na identificação dos integrantes com a organização e o que ela representa. Pode-se, assim, supor que em um processo de empresarização o tipo de controle que viria a predominar nos clubes de futebol seria o controle burocrático. No entanto, na medida em que todo controle e toda forma organizacional supõe um conjunto de valores, não se pode supor que o controle difuso desaparecerá, mas que cederá parte do espaço ocupado ao controle burocrático e que, provavelmente, os valores compartilhados serão transformados. Além disso, pode-se supor que, na medida em que os clubes se espelhem em técnicas atuais de gestão empresarial, eles desenvolvam práticas claramente destinadas a promulgar certos valores, notadamente, vinculados ao "mundo-empresa", entre seus integrantes. 


\section{A pesquisa: análise dos clubes de futebol em Santa Catarina}

Como já destacamos anteriormente, analisamos neste estudo o processo de empresarização de sete clubes que no período compreendido entre 2000 e 2004 participaram da série A1 do campeonato catarinense de futebol, ou seja: Avaí, Chapecoense, Criciúma, Figueirense, Joinvile, Marcílio Dias e Tubarão. Além do processo de empresarização em cada um desses clubes, procuramos perceber as transformações do controle organizacional e sua relação com o avanço do processo de empresarização.

O processo de empresarização parece bastante evidente em alguns clubes. Isso já fica claramente destacado no primeiro traço do tipo ideal de empresa de Solé que analisamos. O traço concepção, produção e venda de mercadoria nos clubes de futebol pode ser mais bem compreendido se considerarmos o fato de que essas organizações originam-se do desejo de agrupamento, diversão coletiva e sustentam-se pela identificação dos participantes e pelo seu desejo de pertença. Isso porque os clubes parecem usar esse desejo de pertença para despertar nos torcedores o desejo de comprar os produtos comercializados. A idéia que parece ser transmitida é que a posse desses produtos é o que vincula o torcedor ao clube. Não é mais a participação, o conhecimento da história do time, a proximidade com a equipe ou o simples sentimento nutrido pelo clube, mas a camiseta, a bandeira e muitos outros produtos comercializados em locais próprios ou não. Esse processo passou por uma transformação rápida. Na Chapecoense, até 1993 nem se pensava em vender camisa do clube, segundo um dos entrevistados. Quando um torcedor queria a camisa, o presidente pegava uma usada e dava ao torcedor. Hoje, embora o clube não tenha sua própria loja, já comercializa alguns produtos. Com essa inserção do mercado nos clubes de futebol, os próprios jogadores passam a ser negociados como mercadoria. No Joinville, os primeiros produtos comercializados parecem ter sido justamente os jogadores, até entrar em vigor a Lei Pelé. Segundo os entrevistados, antes se comprava jogador barato para vender mais caro. Na época atual, os clubes apresentam um número maior de produtos comercializados, embora nem todos comercializem de forma atuante, como é o caso do Tubarão e da Chapecoense que não têm loja do clube. A maioria dos outros clubes vende em lojas próprias, produtos como camisetas, chaveiros, bonés, tocas, bandeiras, relógios de parede e calções do clube. Aqui, o Figueirense se destaca com a venda de 120 produtos licenciados com sua marca. A comercialização de espaços de propaganda nos estádios (placas estáticas), assim como o televisionamento dos jogos - patrocinados por uma rede de TV local, também aparece como uma das formas de captação de recursos nos clubes, sendo citado de maneira geral nas entrevistas.

Muitas das questões financeiras sempre foram resolvidas de maneira bastante informal, em reuniões com os diretores e, sobretudo, diretamente com os presidentes, o que indica uma fraca utilização de documentos para registros contábeis e controles financeiros, característicos de processos empresariais. Historicamente, clubes como o Avaí e Figueirense (até 1999), o Joinville (até 2003) e o Tubarão (até os dias atuais) utilizavam o livrocaixa como modo de formalizar sua área contábil. O Marcílio Dias sempre teve sua parte financeira ligada ao voluntariado, assim como o Criciúma; ou seja, um simpatizante ou torcedor realizava voluntariamente as tarefas de registro para o clube. O Avaí atualmente já apresenta sistemas de controle informatizados na área contábil, evidenciando uma transformação bastante significativa no que diz respeito ao tratamento dessas atividades pelos clubes.

Ainda com relação aos registros contábeis e controles financeiros, a utilização de contratos escritos sempre esteve presente, na medida em que os clubes estabeleciam relações formais com jogadores ou funcionários. Podese, no entanto, perceber uma maior frequiência no uso de contratos, na medida em que os clubes passam a negociar com patrocinadores em maior proporção, mas também com outras organizações que dão apoio aos processos de controle internos. Esse é o caso do Figueirense e do Avaí, que asseguram a cobrança de mensalidades dos sócios através de um contrato com a empresa de energia local, ou ainda através da utilização de boletos bancários. Todos os clubes possuem um setor financeiro, no Figueirense há uma diretoria financeira. Já no Chapecoense, uma empresa com a qual foi assinado um contrato de co-gestão se encarrega das atividades financeiras.

O Figueirense se destaca nas relações comerciais. Para a reforma do estádio, o Figueirense contratou uma empresa americana e, durante um período (1999), assinou contrato com uma empresa pertencente a dois exjogadores, para assegurar a "gestão de futebol" e captação de jogadores, conforme um dos entrevistados decla- 
rou. O Tubarão também fez um contrato com a empresa Mundo do Futebol, uma empresa alemã que manteria o clube financeiramente e trabalharia com a formação e revelação de jogadores. O contrato firmado em 2000 foi rescindido dois anos depois.

O setor jurídico também apresenta situações diversas nos clubes. Em alguns, como Avaí, Marcílio Dias e Tubarão, as atividades jurídicas são asseguradas por voluntários. Em outros, como no Criciúma, por funcionários especializados. Já no Chapecoense e Figueirense, advogados independentes trabalham através do pagamento de honorários.

Todos os clubes estudados têm o estatuto legal de organizações sem fins lucrativos e, até recentemente, a maioria das atividades era realizada por voluntários. Os indivíduos se aproximavam do clube por gostarem de futebol, por serem torcedores e, assim, realizavam as atividades necessárias, embora algum trabalho assalariado tenha estado presente desde o início em alguns clubes. Atualmente, essa relação começa a se inverter e o número de voluntários passa a se restringir à diretoria, que, legalmente, em organizações sem fins lucrativos, não pode ser remunerada. No entanto, algumas limitações relacionadas ao estatuto legal dos clubes vêm sendo solucionadas através de recursos como a criação, pelo Figueirense, de uma empresa (Figueirense Participações) para administrar o clube durante 30 anos. A Chapecoense também passou a administração de seu departamento de futebol a uma empresa local (Mastervest). O Tubarão utiliza a Associação Amigos do Esporte Clube Tubaronense para arrecadar recursos. É a presença dessas empresas na gestão dos clubes que explica, por exemplo, o fato de o diretor financeiro do Figueirense ser remunerado. Como funcionário da Figueirense participações, o diretor é remunerado por esta e presta serviços cotidianamente na sede do clube.

Apesar destes recursos, a maioria dos entrevistados afirma que os clubes são deficitários. A Chapecoense seria fechada em 2001 devido à falta de dinheiro para manutenção. Até hoje o clube vive em situação financeira difícil, apesar de a parceria (co-gestão) com a Mastervet ter sido feita no intuito de ajudar financeiramente o clube. O Joinville, só em 2004, depois de 30 anos de fundação, conseguiu inaugurar seu estádio (financiado pela Prefeitura Municipal de Joinville, segundo entrevistado). A exceção é o Figueirense, que, segundo entrevistados, deve sua saída da crise à nova política implantada pela empresa administradora. Pelos relatos pode-se observar que não havia uma clara separação entre os recursos do clube e os recursos do presidente. Muitas das aquisições de jogadores parecem ter sido feitas com recursos privados dos presidentes. Evidentemente, com a venda do passe, parte dos recursos deveria retornar aos investidores, os presidentes. Essa é uma prática apontada ao mesmo tempo como salvadora de alguns clubes e, também, como forma de uso dos clubes pelos presidentes.

Com a impossibilidade de negociação dos passes dos jogadores, os clubes passam a ver as categorias de base como aquelas nas quais podem investir para obter recursos. O Figueirense tem um Centro de Treinamento (CT) - esse comprado pela Asfig (Associação dos Torcedores do Figueirense) na década de 1970. Os outros clubes buscam investir nessa área, segundo a maioria dos entrevistados. O problema para muitos dos clubes é o investidor, pois necessitam de recursos iniciais volumosos para construir seus centros de treinamento. De uma maneira geral, a maioria dos entrevistados aponta a formação de jogadores como a saída percebida para a obtenção de recursos. Pode-se, portanto, concluir que os jogadores constituem o principal produto dos clubes de futebol que se aproximam do tipo ideal de empresa.

A torcida, em nenhum dos clubes, foi identificada como a principal forma de obtenção de recursos. O Figueirense, nesse ponto, possui 11 mil sócios e, mesmo assim, não tem a torcida entre suas quatro principais fontes de recursos. Depois da comercialização de jogadores, são os patrocínios que constituem fontes importantes de recursos para os clubes, assim como os contratos com as empresas de mídia para a transmissão dos jogos.

Embora a reconstituição histórica do processo de empresarização não tenha ficado clara através dos dados que conseguimos coletar, os entrevistados afirmam que não se utiliza a linguagem que hoje se utiliza nos clubes. Atualmente fica mais clara, nas entrevistas, a presença de uma linguagem mais empresarial. Os clubes que demonstraram isso mais intensamente foram o Figueirense - ao tratar de perfil de funcionários, equilíbrio orçamentário, gestão de pessoas, licenciamento de produtos, royalties e marketing; e o Joinville, com a utilização de trechos como: o futebol começou a ter uma grande transformação como negócio, ramo do entretenimento, clubes consumidores de jogadores, desbravar outros mercados, antes o consumo era local, visão de mercado, marketing esportivo, cenário turbulento, profissionalizar a gestão. padrão de exigência de qualidade, índices 
de controle e endomarketing. Os clubes que mais se distanciam do uso dessas expressões são Criciúma, Marcílio Dias e Tubarão.

No que diz respeito ao controle organizacional, os clubes apresentam historicamente características muito semelhantes, nas quais o controle difuso é predominante, ou seja, a principal forma de coordenação e controle das atividades residia no compartilhamento de valores e na identificação com o clube, não havendo uma linha hierárquica clara, nem procedimentos burocráticos para a garantia de cumprimento das tarefas. Mesmo o controle direto que poderia ter aparecido de forma mais intensa, parece, segundo as entrevistas, não ter desempenhado um papel importante e claro nos clubes estudados. Nesses clubes, no passado, segundo os entrevistados, o presidente decidia junto com os diretores (amigos) do clube, que eram convidados - e ainda o são, para exercer determinadas posições. O futebol era um hobby segundo um dos entrevistados. O horário nunca foi rígido em nenhum dos clubes estudados, e os entrevistados não indicam a presença de autoridade coercitiva e supervisão direta. Ao que tudo indica o controle era, sobretudo, um controle por pares que compartilhavam um conjunto de valores relacionados ao gosto pelo futebol e à identificação com o clube.

A análise das transformações do controle organizacional nos sete clubes de futebol, embora não apareça de forma tão clara quanto o processo de empresarização, pode indicar uma tendência. A formalização como o primeiro indicador do controle burocrático parece completamente ausente dos clubes no passado. O uso de regras formais, segundo um dos entrevistados do Tubarão e do Joinville, não foi identificado devido ao fato do clube ser pequeno e de todos se conhecerem no clube. A formalização aparece limitada aos contratos de trabalho. Atualmente os clubes demonstram uma mudança num sentido formalizador, devido às atas das reuniões, como foi dito por entrevistados do Figueirense, Marcílio Dias e do Joinville; e da mesma forma, através das comunicações internas no Avaí, Figueirense e Marcílio Dias. Na Chapecoense há uma ficha para avaliar os funcionários atualmente e também há uma maior formalização vinculada a obrigações fiscais decorrentes das exigências da Lei Pelé. A própria preocupação com a gestão contábil e financeira parece levar os clubes, atualmente, a um processo de formalização mais acentuado.

Em relação a requisitos técnicos, em nenhum dos clubes os entrevistados disseram ter havido tal prática no passado. Um entrevistado do Criciúma afirmou que antes se aprendia trabalhando. Atualmente o Avaí utiliza o Senac (o diretor do clube é diretor regional do órgão) para que seus funcionários aprendam outras funções que possam ser utilizadas no clube, e o Figueirense capacita alguns funcionários para utilização da parte informatizada ligada à contabilidade e às catracas eletrônicas. No entanto, à medida que o trabalho se profissionaliza e se divide, a exigência de conhecimentos específicos aumenta nos clubes.

A complexidade foi um dos indicadores que mais evoluiu. No Avaí, há 12 anos, o serviço realizado na parte administrativa era, e ainda é um pouco, "quebra-galho". Hoje o clube apresenta uma maior definição dos cargos e das funções. O Joinville e o Tubarão parecem ter definido funções há mais tempo. Atualmente o Joinville utiliza organograma que estabelece a função de cada integrante e o Criciúma apresenta o uso de cronograma de execução de atividades. A divisão vertical e horizontal do trabalho tem, portanto, desenvolvido-se nos clubes, embora essa transformação apareça concentrada em alguns dos clubes analisados.

A tomada de decisão era fundamentalmente informal em todos os clubes. As reuniões informais aconteciam fora do horário de trabalho, uma vez que a diretoria voluntária executava outras atividades em empresas privadas e órgãos estatais. Atualmente a tomada de decisões apresenta características muito diferentes. No Figueirense, quem decide é a Figueirense Participações juntamente com o Figueirense Futebol Clube. Na Chapecoense quem decide nos dias atuais é a empresa que gerencia o departamento de futebol, a Mastervet (contrato de cogestão). Nos demais clubes, embora não se evidencie essa passagem do controle do processo decisório tão fortemente para um órgão externo, pode-se perceber uma preocupação maior em estabelecer mais claramente as responsabilidades no que diz respeito às decisões, o que pode levar a uma centralização maior.

A profissionalização não era, no passado, uma preocupação dos clubes, mas já há algum tempo vem paulatinamente se expandindo, tendo evidentemente, iniciado esse processo no departamento de futebol dos clubes, na medida em que a preparação de jogadores e o apoio aos atletas foram se tornando uma especialidade. Atualmente, essa preocupação se expande para quase todas as áreas dos clubes. No Avaí e no Criciúma já há a contratação de pessoas com segundo grau, no mínimo, para a parte administrativa. A diferença é que o Avaí 
possui contador no clube, e no Criciúma, além do contador com um auxiliar, há dois advogados e um estagiário fixos. O Joinville também está mudando em relação a essa questão profissional, apesar de seu gerente de marketing e de negócios ser formado em educação física. Todavia, já há um contador no clube. No Figueirense, desde 1999 há uma empresa de recursos humanos que faz a contratação de pessoal, e para a parte administrativa e de assessoria, já é exigido o segundo grau.

Uma transformação importante que podemos perceber nos clubes de futebol da série A1 de Santa Catarina diz respeito ao compartilhamento de valores. Toda forma organizacional é portadora ou é investida de certos valores. Os relatos dos entrevistados evidenciam uma tendência significativa de mudança nos valores compartilhados pelos integrantes dos clubes. Os entrevistados destacam que o sentimento de união e a vontade de fazer o melhor pelo clube eram característicos daqueles que executavam as atividades necessárias ao funcionamento dos mesmos no passado. Alguns entrevistados do Avaí relatam que mesmo com os salários atrasados os integrantes se uniam pelo bem do clube. Atualmente, a relação predominante é aquela habitual entre empregador e empregados e, diante de salários atrasados, os empregados levam suas reclamações à Justiça. Parece bastante evidente que os valores antes compartilhados dão lugar a outros mais característicos de organizações empresariais. Assim, os ganhos, a eficiência e os resultados passam a ser mais valorizados do que a dedicação, o sentimento e a lealdade.

Essa mudança também se manifesta na forma de selecionar os novos integrantes. No passado usava-se predominantemente a indicação, ou seja, integrantes dos clubes ou pessoas próximas indicavam outras pessoas para serem contratadas. Atualmente esse mecanismo é utilizado ainda, mas a análise de currículo já é um mecanismo de seleção no Avaí, Criciúma e Joinville e, no Figueirense não há manifestação de que ainda se use a indicação por um integrante. Essa é uma transformação esperada em organizações que se profissionalizam, como mostrou a análise do processo de empresarização nos clubes.

Os entrevistados apontam para a ausência de programas de ação no passado dos clubes. Parecia haver uma constante administração das necessidades mais urgentes com um processo de decisão bastante centralizado na diretoria que, em face de alguma necessidade toma medidas imediatas, como contratações de última hora em momentos de desempenho insatisfatório durante o campeonato, como relatam alguns dos entrevistados do Avaí, Joinville, Tubarão e Marcílio Dias. Os demais clubes parecem vir estabelecendo cada vez mais claramente programas de ação que estabelecem a direção seguida pelo clube, sobretudo, aqueles que contam com administração de empresas, como o Figueirense e a Chapecoense. Processos mais claros de planejamento parecem, então, ser adotados paulatinamente nos clubes que se aproximam mais do tipo ideal de empresa desenvolvido por Solé. Essa relação ficará mais clara na análise comparativa dos resultados que apresentaremos a seguir.

\section{Empresarização e controle: análise comparativa dos dados}

O desenvolvimento de uma concepção mais mercantil evidenciada pela proliferação de produtos e serviços comercializados pelos clubes parece ter uma clara influência no processo de divisão do trabalho. Os clubes mais empresarizados como Joinville e Figueirense tendem a apresentar um número maior de diretorias e departamentos e, principalmente, de departamentos específicos para tratar de aspectos relacionados ao mercado. Atualmente, no Joinville e no Figueirense, o departamento de marketing é o responsável pelo desenvolvimento de produtos e serviços. $\mathrm{O}$ desenvolvimento da preocupação com processos contábeis e financeiros também tem impacto na divisão do trabalho, levando tanto à criação de novos departamentos especializados quanto a uma maior profissionalização dos clubes.

O desenvolvimento de relações assalariadas através do processo de empresarização parece ser um dos traços que se relacionam tanto com o controle burocrático quanto com o difuso. A crescente complexidade estrutural manifestada através da divisão horizontal e vertical do trabalho implica, nessas organizações, a substituição de integrantes voluntários que mantinham laços afetivos com os clubes, por trabalhadores que preenchem os requisitos técnicos dos cargos e desenvolvem um vínculo instrumental com os clubes. Essas são transformações bastante evidentes em clubes como Figueirense, Criciúma, Joinville e Avaí. 
As transformações observadas na linguagem são as que mais evidenciam a mudança de valores compartilhados nos clubes, indicando impactos significativos nos clubes que mostram maior nível de empresarização nos mecanismos de controle difuso. Em clubes como a Chapecoense, Joinville e Figueirense e, em menor escala, Avaî $^{2}$ e Criciúma, percebe-se uma forte utilização de expressões características daquelas utilizadas em empresas. Essas transformações não implicam desaparecimento ou enfraquecimento do controle difuso, mas a substituição de valores. Se antes as relações afetivas, de lealdade e de pertença eram predominantes, atualmente valores como sucesso e desempenho parecem alcançar pouco a pouco maior destaque. Uma vez que o processo de empresarização não está totalmente concretizado nesses clubes, pode-se perceber um enfraquecimento do controle difuso, uma vez que sob valores tradicionais ainda não foram totalmente substituídos. Isso é evidente pela presença de conflitos internos e externos explicitados nesse processo de mudança; por exemplo, em manifestações das torcidas quando acusam os jogadores de agirem exclusivamente em função de objetivos materiais.

No quadro 1 procuramos apresentar as caracterizações que foram observadas ao longo do processo de análise da empresarização e do controle dos clubes da série A1 do campeonato catarinense. A fim de facilitar a compreensão, caracterizamos o processo em dois momentos, o atual e um segundo que busca refletir as características mais evidentes dos clubes no passado, que denominamos no quadro de histórico. Utilizamos uma escala para avaliar a presença de cada indicador nos dois momentos avaliados: fraco (FR), no caso de não ter sido identificado nada em relação ao indicador; fraco/moderado (FR/M), para um ou alguns indicadores sem muita relevância; moderado (M), mostrando um início de evolução; moderado/forte (M/FO), para o caso de uma evolução significativa ; e forte (FO), quando o indicador foi evidenciado claramente.

Quadro 1- Resumo do processo de empresarização e sua relação com os clubes estudados

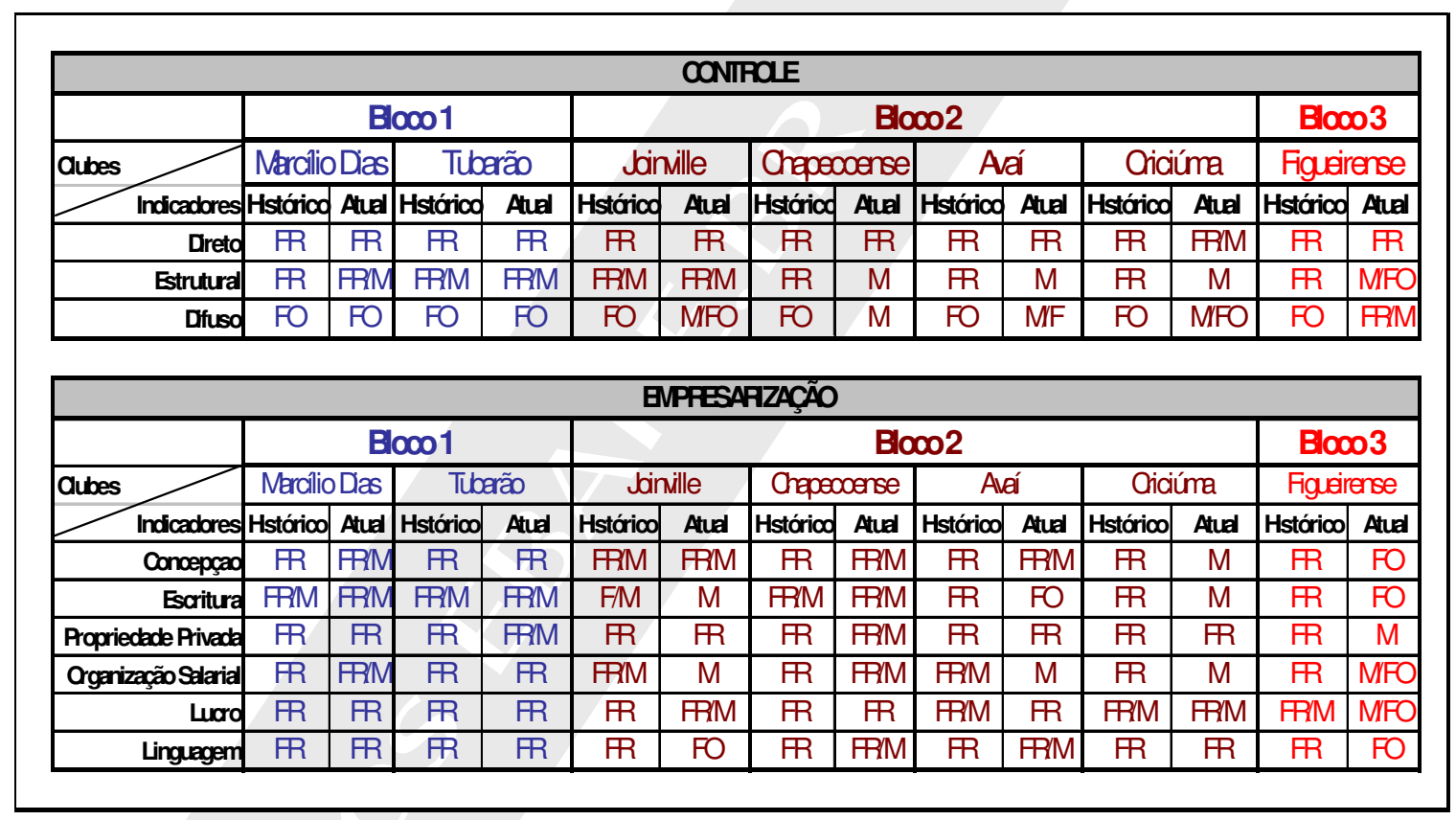

Fonte: elaboração própria.

Foi possível, dessa forma, classificar os clubes em três blocos que expressam o estado atual de desenvolvimento dos processos de empresarização e controle. No bloco 1 classificamos Marcílio Dias e Tubarão como os clubes que apresentam os menores indícios de empresarização e nos quais o controle difuso aparece mais intensamente que o controle estrutural ou direto. No bloco 2, onde classificamos Joinville, Chapecoense, Avaí e Criciúma, pode-se perceber níveis moderados de empresarização e, no que diz respeito ao controle, um enfraquecimento dos valores tradicionais que ligavam os integrantes aos clubes, atenuando o controle difuso, assim como níveis um pouco mais desenvolvidos de controle estrutural. No bloco 3, aparece claramente destacado dos demais o Figueirense. Esse clube é aquele que apresenta os níveis mais elevados de empresarização, bem como desenvolvimento mais significativo de controle estrutural. É importante destacar mais uma vez que nossa avaliação do controle difuso está relacionada com o processo de transição dos valores compartilhados nos clubes, 
como explicamos anteriormente; ou seja, os valores tradicionais estão sendo substituídos por novos valores, característicos da empresa, mas estes ainda não estão consolidados.

\section{Considerações finais}

A análise parece evidenciar de forma bastante clara que vários dos clubes de futebol da série A1 do campeonato catarinense vêm passando por um processo importante de empresarização. Se, por um lado, o processo ainda não está totalmente consolidado, por outro, parece haver claros sinais de tendência evolutiva. Nesse sentido, os traços relacionados à organização salarial, à organização com escritura e contabilidade e à linguagem empresarial aparecem com maior destaque tanto em intensidade quanto em amplitude. O traço concepção, produção e venda de mercadorias só não mereceu o mesmo destaque porque ainda é significativo o número de clubes que não comercializam produtos diretamente. No entanto, não podemos deixar de destacar que nos clubes mais empresarizados o produto principal é o jogador e, que este constitui um produto em qualquer dos clubes. Se por um lado o marco legal restringe atualmente o comércio de jogadores, por outro há uma brecha já encontrada na comercialização das categorias de base, além de outras relacionadas a multas por quebras de contrato que propiciam resultados semelhantes aos clubes. A comercialização do espetáculo jogo é também um alvo da maioria dos clubes e isso é evidenciado pela celebração de contratos com a mídia.

No que diz respeito ao controle organizacional ao longo da história dos clubes de futebol, ficou bastante claro que, de maneira geral, o controle organizacional tem uma evolução marcada pela complexidade que acompanha o crescimento das organizações. O controle normativo parece ter sido o que teve maior destaque no passado nessas organizações. Atualmente, há uma transformação nos valores compartilhados pelos integrantes dos clubes e valores característicos do ambiente de negócios estão, dessa forma, mais presentes, notadamente os de eficiência, profissionalismo e mercado. O controle difuso, denominado por Perrow (1990) como menos intrusivo, sofre essa transformação ao mesmo tempo em que mecanismos impessoais e formais passam a fazer parte da organização do trabalho em alguns clubes.

O controle direto, que segundo Mintzberg (1995) e Wagner e Hollenbeck (2000) é característico de organizações pouco estruturadas e com pequeno tamanho, no entanto, não apresenta destaque nos clubes de futebol estudados. Isso possivelmente tem relação com a ausência de clareza dos níveis hierárquicos e com o forte compartilhamento de valores entre os membros do clube, além do conhecimento do funcionamento da organização, que permitiam que os membros não necessitassem de ordens explícitas e claras, uma vez que, pelos relatos, após as decisões, todos sabiam o que deveria ser feito.

Em uma organização burocrática os mecanismos de controle são sobretudo estruturais, de acordo com Motta (2002) e Monte (2003). O controle vem se fundamentar em normas escritas, em uma estrutura hierárquica mais definida e em funções mais especializadas. Tal tipo de controle teve uma evidente evolução, já que as regras, as comunicações internas e as atas das reuniões, assim como o aumento de profissionais especializados, começam a fazer parte do quadro de pessoal dos clubes. Uma crescente complexidade nas funções, tal como descrita por Hall (1984), pôde ser identificada, tanto na diferenciação vertical quanto na horizontal. Mecanismos impessoais de controle passam a fazer parte das organizações futebolísticas estudadas em Santa Catarina, atualmente, rumo a uma maior formalização de ações, ou seja, planejando regulamentos e padrões que possam ser utilizados para controlar o comportamento organizacional (WAGNER; HOLLENBECK, 2000). Podemos considerar que a análise permite supor que o processo de empresarização, tal como descrito por Solè (2004), mesmo não sendo intenso e homogêneo em todos os clubes estudados, parece ter impacto sobre os tipos de controle mais enfatizados nessas organizações, sobretudo, na observação de um maior destaque dado ao controle estrutural. Nesse sentido, entre os traços de empresarização, o lucro e a propriedade privada foram, segundo as entrevistas, os que menos evoluíram. Todos esses clubes têm em seus estatutos a designação de instituição sem fins lucrativos, mas é importante sublinhar a intenção de alteração da personalidade legal nos clubes: Joinville, Avaí, Chapecoense e Figueirense, embora ainda não tenha ocorrido, o que indica uma mudança nos valores dos clubes de certa forma. Até agora, parece ter havido uma adaptação ou utilização de outro mecanismo para administrar alguns desses clubes. Para o Chapecoense, a parceria com uma empresa para administrar o departamento de futebol, co-gestão, e no Figueirense, a constituição de uma empresa para gerenciar os negócios do clube. 
A linguagem é um dos traços que mostram mais acentuadamente a empresarização de alguns clubes. No entanto, em muitos clubes essa nova linguagem mescla-se com um discurso sobre a paixão pelo clube. No Figueirense, no entanto, um dos diretores acentuou que o clube não deve ser administrado pela paixão, estendendo essa necessidade aos torcedores e seu relacionamento com o clube e colocando-os na posição de clientes. As idéias de regras e metas financeiras são bastante presentes nos discursos, assim como expressões características da gestão empresarial. No clube Marcílio Dias, contudo, foi enfatizado que não seria honesto mudar o estatuto do clube para uma sociedade anônima, o que evidencia que, ao menos por enquanto, a empresarização não é consenso e que ainda há resistência.

Da mesma forma que os estudos sobre mercantilização enfatizam a mudança nos valores de algumas organizações, o estudo sobre empresarização também evidenciam a mudança de valores. O processo de empresarização, a partir dos traços estudados, parece efetivamente relacionado com as transformações do controle. Ainda que o processo de empresarização não apresente intensidade em todas as suas características. Se funcionários já começam a reclamar dos salários atrasados indo à Justiça cobrar os direitos, se o torcedor passa a ser visto como um cliente, se outras organizações (no caso, empresas privadas) passam a ser administradoras de alguns clubes, se cada vez mais pessoas assalariadas e formadas em determinadas áreas passam a compor o quadro dos clubes, acredita-se que o caráter difuso tende a migrar em alguns pontos para o estrutural. É o início da burocratização dessas organizações e a inclusão de novos valores.

Nos sete clubes estudados teve-se uma idéia mais clara do quanto alguns clubes, desde sua fundação, preservam ou comungam de certos valores sem perspectivas maiores no sentido empresarial. Um clube se destaca no que diz respeito à empresarização, no caso o Figueirense, da mesma forma que os outros clubes vêem neste um exemplo a ser seguido, assim como foi dito nas entrevistas realizadas no Avaí e no Joinville. O estudo de outros clubes do campeonato catarinense poderia, talvez, deixar mais clara a preservação dos valores e a resistência ao processo de empresarização.

Em síntese, a análise da evolução do controle organizacional nos remete a uma configuração bastante distinta no momento atual, ficando bastante evidente a intensificação da utilização de mecanismos burocráticos de controle em detrimento dos mecanismos culturais do controle difuso através dos valores compartilhados anteriormente, além de uma crescente transformação dos valores nos clubes estudados. 


\section{Referências}

BLAU, P.; SCOT, W. Organizações formais. 1.ed. São Paulo: Atlas, 1970.

BOURDIEU, P. Questões de sociologia. Rio de Janeiro: Marco Zero, 1983.

BRUNORO, J. C. Futebol 100\% profissional. São Paulo: Gente, 1997.

BURRIS, B. H. Technocratic organization and control. Organization Studies, v.10, n.1, p.1-22, 1989.

CARVALHO, C. A. Poder, conflito e controle nas organizações modernas. Maceió: Ufal, 1998.

; GONÇALVES, J.; ALCÂNTARA, B. O lúdico, o profissional e o negócio no futebol. In: Organizações, cultura e desenvolvimento local: a agenda de pesquisa do Observatório da Realidade Organizacional. Recife: Edufepe, 2003. cap.12, p.235-254.

CHIAPPELLO, E. Les typologies des modes de contrôle et leurs facteurs de contingence: un essai d'organisation de la littérature. Comptabilité-Contrôle-Audit, tome 2, v.2, sept. 1996.

COURPASSON, D. Managerial strategies of domination - power in soft bureaucracies. Organization Studies, v.21, n.1, p.141-161, 2000.

DAS, T. K. Organizational control: an evolutionary perspective. Journal of Management Studies, New York, v.26, n.5, p.459-475, Sept. 1989.

ETZIONI, A. Organizações modernas. São Paulo: Pioneira, 1967.

FARIA, J. H.. Economia politica do poder. Curitiba: Juruá, 2004.

HALL, Richard H.. Organizações: estrutura e processos. 8. ed. Rio de Janeiro: Prentice Hall do Brasil, 1984.260 p.

HATCH, M. J. Organization theory. Modern, symbolic and postmodern perspectives. Oxford: Oxford University Press, 1997.

HOFSTEDE, G. Management control of public and not-for-profit activities. Accounting, Organizations and Society, v.6, n.3, p.193-211, 1981.

KASZNAR, I. K. O esporte como indústria: solução para criação de riqueza e emprego. Rio de Janeiro: Confederação Brasileira de Voleibol, 2002.

MARCONI, M. A.; LAKATOS, E. M. Técnicas de pesquisa: planejamento e execução de pesquisas, amostragem e técnicas de pesquisa, análise e interpretação dos dados. São Paulo: Atlas, 1990.

MINTZBERG, H. Criando organizações eficazes: estruturas em cinco configurações. São Paulo: Atlas, 1995.

MONTE, T. C. Parcerias entre ONGs e empresas: uma relação de poder camuflada. In: Organizações, cultura e desenvolvimento local: a agenda de pesquisa do Observatório da Realidade Organizacional. Recife: Edufepe, 2003. cap.13, p.255-274.

MOTTA, F. C. P. Teoria geral da administração. São Paulo: Pioneira, 2002.

PAGÈS, M. 0 poder das organizações: a dominação das multinacionais sobre os indivíduos. São Paulo, Atlas, 1993.

PERROW, C. B. Análise organizacional: um enfoque sociológico. São Paulo: Atlas, 1990.

PILLATI, L. A. Reflexões sobre o esporte moderno: perspectivas históricas. In: I Prêmio Indesp de literatura desportiva. Brasília: Instituto Nacional de Desenvolvimento do Desporto, v.1, 1999. cap.4, p.257-288.

RAMOS, A. G. A nova ciência das organizações. Rio de Janeiro: FGV, 1989.

ROCHE, F. P. Gestão desportiva - planejamento estratégico nas organizações desportivas. Porto Alegre: Artmed, 2002.

SILVA, R. C. Controle organizacional, cultura e liderança: evolução, transformações e perspectivas. Revista de Administração Pública RAP, Rio de Janeiro, v.37, n.4, p.797-816, jul./ago. 2003.

SOLÉ, A. ¿Qué es una empresa? Construcción de un idealtipo transdisciplinario. Paris, 2004. Work paper.

TANNENBAUM, A. S. 0 controle nas organizações. Petrópolis: Vozes, 1975.

TRIVIÑOS, A. N. S. Introdução à pesquisa em ciências sociais: a pesquisa qualitativa em educação. São Paulo: Atlas, 1987.

VIEIRA, Marcelo Milano Falcão Vieira; ZOUAIN, Deborah Morais(Org.). Pesquisa qualitativa em administração. Rio de Janeiro: FGV, 2004. 224 p.

WAGNER III, J. A.; HOLLENBECK. Comportamento organizacional: criando vantagem competitiva. São Paulo: Saraiva, 2000. 
${ }^{1}$ Apresentamos aqui uma rápida abordagem das transformações do futebol. O tema já foi desenvolvido em outras publicações que podem ser consultadas (cf. CARVALHO; GONÇALVES; ALCÂNTARA, (2003).

${ }^{2}$ Quando da redação final deste artigo para publicação nesta revista, o Avaí, que à época da coleta de dados não tinha local próprio para a comercialização de produtos, já apresentava uma loja específica no principal shopping center de Florianópolis. 